\title{
Dayanıklı Tüketim Malları Sektöründe Şikayet Yönetimine Yönelik Gri ilişskisel Analiz Tekniği Uygulaması
}

Hale Nur GÜLER ${ }^{1}$

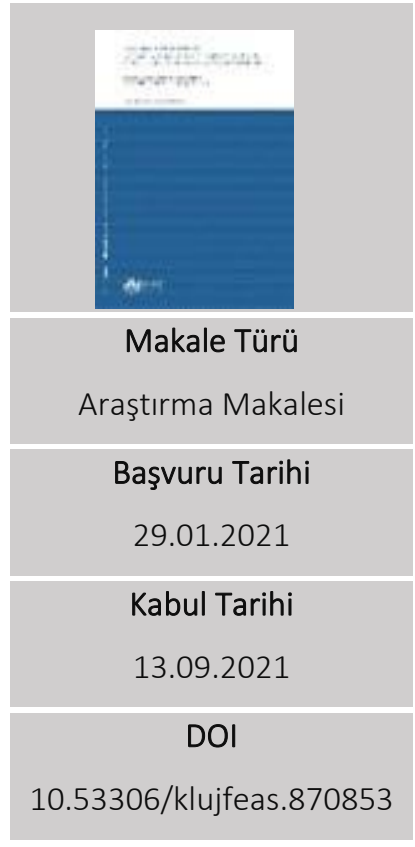

\begin{abstract}
Öz
Gelişen teknoloji, müşteri beklentilerinin artması ve müşterilerin birçok kanaldan şikayetlerini iletebilmeleri nedeniyle şirketlerde şikayet yönetimi politikaları daha da önemli hale gelmiştir. Müşteriler şirketlerle ilgili görüşlerini iletip problemleri için çözüm beklemekte ve memnun olmadıkları çözümler içinde birçok kanaldan yorum iletebilmektedir. Şirketlerin şikayetlerin önlenmesi ve oluşan şikayetlerin etkinlikle çözülebilmesi için başarılı şikayet yönetimi politikalarına ihtiyaçları vardır. Bu çalışmada dayanıkı tüketim malları sektöründe mal ve hizmet sunan şirketlerin şikayet yönetim politikalarının etkinliği çok kriterli karar verme tekniklerinden gri ilişkisel analiz yöntemiyle belirlenmesi amaçlanmıştır. Dayanıklı tüketim malları sektöründe bulunan şirketlere ait veriler şikayetvar.com isimli müşteri şikayetleri ile şirketleri birleştiren platform olan internet sitesinden ve şirketlerin resmi internet sitelerinden elde edilmiştir. Çalışmada şikayet yönetimi politikalarının etkinliğinin belirlenmesinde çözüm oranı, çözüm süresi, memnuniyet puanı ve iletişim kanal sayısı olarak dört kriter esas alınarak şirketler sıralanmıştır. Buna göre yapılan analiz sonucuna göre Simfer, Arçelik ve Vestel' in ilk üç sırada yer aldığı görülmektedir.
\end{abstract}

Anahtar sözcükler: şikayet yönetimi, müşteri şikayetleri, dayanıklı tüketim malları sektörü, gri ilişkisel analiz.

${ }^{1}$ Dr., Bağımsız Araştırmacı, glrhalenur@gmail.com, ORCID: 0000-0002-6333-1849 


\title{
Application Of Gray Relational Analysis Technique On Complaint Management In The Durable Goods Industry
}

\author{
Hale Nur GÜLER²
}

\begin{abstract}

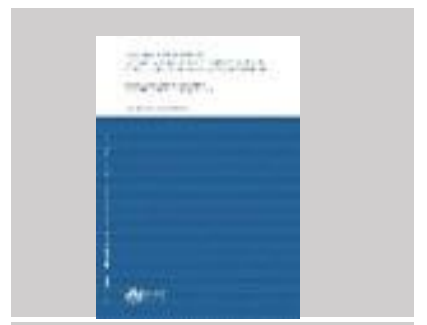

Article Type

Research Article

Application Date

2021-01-29

Acceptance Date

2021-09-13

DOI

10.53306/klujfeas.870853

Complaint management policies have become even more important in companies due to the developing technology, the increase in customer expectations and the ability of customers to convey their complaints through many channels. Customers are waiting for solutions for their problems by conveying their opinions about the companies and can send comments through many channels for solutions they are not satisfied with. Companies need successful complaint management policies in order to prevent complaints and to solve complaints effectively. In this study, it is aimed to determine the effectiveness of the complaints management policies of companies that provide goods and services in the durable consumer goods sector by using the gray relational analysis method, which is one of the multi criteria decision-making techniques. The data of the companies in the durable consumer goods sector were obtained from the official website of the companies, from the website called sikayetvar.com, which is the platform that connects the companies with the customer complaints. In the study, companies are listed on the basis of four criteria as resolution rate, resolution time, satisfaction score and number of communication channels in determining the effectiveness of complaint management policies. According to the results of the analysis made accordingly, it is seen that Simfer, Arçelik and Vestel are in the top three places.
\end{abstract}

Key words: complaint management, customer complaints, durable goods industry, gray relational analysis.

2 PhD., Independent Researcher, gIrhalenur@gmail.com, ORCID: 0000-0002-6333-1849 


\section{Giriş}

Teknolojideki değişim ve gelişim, ülke ve dünyadaki ekonomik gelişmeler, eğitim düzeyinin artması ile müşteri beklentilerinin de arttığını ifade etmek mümkündür. Müşteriler günümüz şartlarında memnuniyetsizliklerini pek çok kanaldan duyurabilmektedir. Şirketlerin müşteri beklentilerini etkin şekilde anlamaları oluşan şikayetlerin beklenenin ötesine geçilerek çözmeleri ve buna bağlı olarak da mal ve hizmetlerinde sürekli geliştirme yapmaları gerekmektedir. Sektörde pek çok alternatifin olması sebebiyle şirketlerin ayakta kalabilmeleri ve rekabet güçlerini koruyabilmeleri için etkili ve başarılı müşteri deneyimleri yaratmaya intiyaçları bulunmaktadır. Bu kapsamda bakıldığında şikayetin şirketlerin imajlarının belirlenmesinde de önemli etkileri bulunmaktadır. Her şikayete bir armağan gözüyle bakan şirketlerin politikalarını buna göre yönettikleri iletilen şikayetler sebebi ile gereken süreçlerinde gelişim sağladıkları ve müşterileri olumlu yönde etkiledikleri bilinmektedir.

Şikayet yönetimi için ürün veya hizmetin müşteriye sunulması sürecinde oluşabilecek tüm şikayetler özenle yönetilip ardından da müşteri davranışı takip edilmelidir. Şirketlerin şikayet yönetimi birimlerinin büyük bir titizlikle oluşturularak bu alanda hizmet vermeye uygun çalışanların seçilmesi gerekmektedir. Müşterilerin şikayetlerini kolaylıkla iletebilecekleri kanalların yönetilmesi önemlidir. Şirketler için veri sağlayabilecek nitelikte sağlıklı şikayet ve memnuniyet verilerinin arşivlenmesi, yenilikçi ve inovatif süreçlerin kurgulanması, müşteri beklentisinin de ötesinde çözüm alternatifleri uygun zaman diliminde sunulması ve müşterinin şikayetinin ardından izlenip davranışlarının belirlenmesi gerekmektedir.

Elektrikli ev aletleri ve beyaz eşya sektörünü kapsayan dayanıklı tüketim malları sektöründe geniş ürün seçeneği bulunmaktadır. Buzdolabından ocağa, çamaşır makinesinden miksere kadar pek çok ürün bu sektörde müşterilere sunulmaktadır. Üretimin artmasında en çok payı olan sektörlerin başında olan ülke ekonomisine katkı sağlayan dayanıklı tüketim sektöründe önemli ölçüde istihdama da katkı sağlanmaktadır. Dayanıklı tüketim malları sektöründe müşterilerin seçebileceği pek çok alternatif marka yer almaktadır. Bu sebeple ürün ve hizmetin kalitesi ve dayanıklılığı kadar süreç içerisinde müşterinin yaşadığı deneyim de oldukça kritik boyuttadır. Şikayetin önlenmesi ya da oluştuktan sonra şirketlerin yaklaşımı müşteri için oldukça önemli karar faktörlerindendir. Şikayet sonucunda doğan memnuniyet ya da memnuniyetsizlik müşterilerin şirketle ve mal ve hizmetleri ile ilişkisini belirlemektedir. Müşterilerin olumsuz izlenimlerini olumlulara göre daha çok paylaştıkları düşünüldüğünde iletilen her bir şikayetin önemi fazladır. Şirketler müşteri memnuniyeti oluşturmak için insan kaynağından başlayarak tüm süreçlerde etkili bir yönetim uygulamak durumundadırlar. Günümüz şartlarında aynı sektörde benzer mal ve hizmet pazarlaması sunan şirketlerin satış sonrası hizmetlerinde ve süreçlerinde farklılık yaratarak müşterileri cezbetmeleri gerekli kılınmaktadır.

Bu çalışmada dayanıkı tüketim malları sektöründeki şikayet politikalarının anlaşılması için sektörle ilgili temel düzeyde bilgiler aktarılmış ardından gri ilişkisel analiz yöntemi açıklanmıştır. Çalışmada sektörde yer alan on şirkete ait veriler şikayetvar.com sitesinden 
GÜLER; Application Of Gray Relational Analysis Technique On Complaint Management In The Durable Goods Industry, 274-291.

ve şirketlerin resmi internet sitelerinden elde edilerek belirlenen kriterler kapsamında şirketlerin şikayet yönetim politikalarındaki etkililikleri gri ilişkisel analiz ile sıralanmıştır. Müşteri odaklı yaklaşım sergilemek zorunda olan şirketlerin şikayet yönetim politikalarındaki durumlarının belirlenmesinin alanla ilgilenen araştırmacılar için yararlı olacağı düşünülmektedir.

\section{1. Şikayet Yönetimi Dayanıklı Tüketim Malları Sektörü ve İlgili Çalışmalar}

Alınan mal ya da hizmet sonucunda beklentilerin karşılanmaması ve tatminsizlik oluşması sonucunda şikayet doğmaktadır (Barlow ve Moller, 2009, s. 38). Ürün ya da hizmeti satın alan tüketicinin olumsuz geri bildirimi şikayettir. Şirketlerin sunduğu ürün ve hizmetle ilgili olumsuz geri dönüş almasıdır (Mensah, 2016, s. 10). Şikayet ettiklerinde müşteri ürün ve hizmetle ilgili bilgi verip olumsuz durumunun tazminini istemektedirler (Blöndal, 2017, s. 22).

Şikayetler gerekli özenle ele alındıklarında şirketler için gelişime olanak sağlamaktadır. Müşterilerin beklentilerinin anlaşılması uygun çözümlerin sunulması şirketleri geleceğe daha güvenle taşımaktadır (Kozak, 2007, s. 2). Ürün ve hizmetle ilgili olumsuz durum yaşayan müşteriler yaşanılan durumu şikayet etmekte ya da şirketle ilgili olumsuz düşünüp markayı terk etmektedir (Scriabina ve Fomichov, 2007, s. 4). Müşterilerin markaları, yeterli ilgi alamadıklarında, ürün ve hizmet kalitesinden memnun kalmadıklarında, rakip firmalar nedeniyle, ürün ve hizmeti elde edecekleri bir tanıdık bulduklarında, taşınma ya da ölüm sebebi ile terk ettikleri bilinmektedir. Şikayet sürecinde başarılı olmak şirketler için müşteri sadakati yaratmaktadır (Yang vd. 2020, s. 203). Müşteri sadakatinin yanı sıra müşteri beklentilerinin analiz edilmesi ile şikayetlerin azaltılması, mal ve hizmet kalitesinin artması, hatanın azaltılması hedeflenmektedir (Alabay, 2012, s. 139; Tronvoll, 2008, s. 23). Şirketlerin şikayet çözüm süreçlerinde etkin olmaları, müşterileri kaybetmeme, ağıdan ağıza iletilen olumsuz durumların paylaşımını engelleme, çapraz satış imkanı, müşterilerin yasal yollara başvurmalarını önlemektedir (Harrison Walker, 2001, s. 401).

Müşteriler satın aldıkları mal ve hizmetin beklentilerini karşılamaması sonucunda şikayetlerini iletmektedir. Müşteriler şikayet çözüm sürecini değerlendirip ardından da markayı terk etme ya da markada kalmayı tercih etmektedirler (Köse, 2007, s. 25). Müşteriler her zaman şikayet iletmezler markadan memnun kalmadıkları durumlarda şikayet iletmedikleri de görülmektedir (Gökdeniz vd., 2011, s. 175). Müşteriler zaman ve çaba harcamaya gerek görmediklerinde, risk almak istemediklerinde, nereye şikayet edeceklerini bilmediklerinde, sonuç alabileceklerine dair inançlarının olmadığı durumlarda şikayet etmemektedir (Burucuoğlu, 2011, s. 60).

Satın aldıkları ürün ve hizmetten bekledikleri tatmini sağlayamayan müşteriler şikayetlerini pek çok kanaldan iletebilmektedir. Halka açık kanallar, şirketlerin kendi oluşturdukları iletişim kanalları, tüketici hakem heyeti, tüketici dernekleri, kanuni yollar ve şikayetleri toplayan internet platformları bu kanallardır (Supriaddin vd., 2015, s. 4; Cho vd., 2002, s.6). Şikayetlerin aile ve arkadaşlara bilgi verme, markayı terk etmek, üst yönetime iletme, yorum ve öneri formları doldurma, şikayet mektubu, dilekçe yazma, kitlesel medya araçlarına iletme, tüketici derneklerine iletilmesi şeklinde yedi farklı yöntemle iletildiği bilinmektedir 
GÜLER; Dayanıklı Tüketim Malları Sektöründe Şikayet Yönetimine Yönelik Gri iliş̧kisel Analiz Tekniği Uygulaması, 274-291.

(Heung ve Lam, 2003, s. 286). Müşteri şikayetleri başarılı şekilde ve özenle ele alınmadığında ağızdan ağıza iletilebilmekte gelecekteki müşterilere ve şirket imajına etki etmektedir (Januszewski, 2004, s. 2).

Müşterilerin olumsuz durumları olumlu durumlara göre iki kat daha fazla dile getirdikleri bilinmektedir (Plymine, 1991, s. 40). Şirketlerin rekabet edebilmeleri ve ayakta kalabilmeleri için şikayetleri müşteri memnuniyetine dönüştürmeleri gerekmektedir. Şikayet çözme kültürü olan şirketlerin müşterilerin rahatlıkla ulaşabilecekleri iletişim kanallarının olduğu ve şikayetlerin açık anlaşııı basit şekilde çözümlendiği belirtilmektedir. Şikayeti etkin şekilde memnuniyete dönüştüren şirketlerin müşteri memnuniyeti araştırmaları yaptıkları bilinmektedir (Robert ve Sandy, 2002, s. 144).

Şirketlerin başarılı şekilde şikayet çözüm yönetimi süreçlerini işletebilmeleri için müşterileri etkin şekilde dinleyip empati kurabilmeleri gerekmektedir. Iletilen şikayet birden fazla açıdan incelenmeli müşteriye kısa sürede kapsamlı ve şeffaf çözüm sunulmalıdır. Şirket içinde şikayet yönetimi ekiplerinde çalışanlar eğitim ve motivasyonel uygulamalarla desteklenmelidir (Yılmaz, Varnalı ve Kasnakoğlu, 2015, s.945). Etkili şikayet yönetimi için müşteriye doğru sorular sorularak ihtiyacı ortaya çıkartılmalı sorun tam olarak anlaşılmalıdır, müşteriye nazik ve kibar şekilde yaklaşılmalı ve gerekli zaman ayrılmalıdır. Gerekli olduğu hallerde müşteriden özür dilenmelidir. Şikayet çözümü ideal sürede olmalı ve müşteri beklentisinin ötesinde çözüm sunulmalı ardından da müşteri memnuniyeti takip edilmelidir (Ramsey, 2016, s. 23).

Şirketler sorunu analiz edip, çözüm alternatiflerini belirleyip, en uygun seçimi yapıp, çözümü izlemelidir. Şirketler, müşterilerin neden şikayetçi olduklarını, beklentilerini ve müşterileri iyi tanımalı, şikayetin şirket için önemini, bu konu için ayrılacak bütçeyi ve tüm bu koordinasyonu sağlayacak olan çalışan beklentilerini özenle takip edip yönetmelidir (Odabaşı, 2009, s. 108; Butelli, 2007, s. 4). Dayanıklı tüketim malları içinde beyaz eşya sektörü, genellikle büyük ev aletleri ve küçük ev aletleri üretilmektedir (Eleren, 2007, s. 49). Türkiye Beyaz Eşya Sanayicileri Derneği (TÜRKBESD)' ne göre beyaz eşya sektörü istihdam katkısı ve ihracattaki etkinliği ile öncü sektörlerdendir. Pek çok sektörde olduğu beyaz eşya sektöründe mal ve hizmet üreten şirketlerin de etkili şikayet yönetimi politikalarına ihtiyacı bulunmaktadır. Müşterilerin kolaylıkla ulaşabilecekleri kanalların bulunması, hızlı çözüm alabilmeleri ve aldıkları çözümler için memnun kalmaları şirketlerin ayakta kalabilmeleri için oldukça önemlidir. Dayanıklı tüketim malları sektörü için yapılan çalışmada ağızdan ağıza iletişimin marka tercihlerine etkisi olduğu görülmüştür (Çiftçi, 2019, s. 10).

Dayanıklı tüketim malları için yapılan bir başka çalışmada da tüketicilerin deneyimsel olumsuzluklar sebebi ile ürünün performansı, satış sonrası hizmetler, markayı tercih etmedikleri ifade edilmektedir. Buna göre müşterilerin markayı tercih etmekten kaçınmalarına müşteri hizmetlerinin, verilen garanti sürelerinin yeterli olmadığı görülmüştür (Ventura, 2013, s. 70). Bu kapsamda bakıldığında şirketlerin müşterilerin tercih ettiği markalar arasında olabilmek için müşteri deneyimi tasarımında ve şikayet yönetimi çözümünde etkili olmaları gerektiği söylenebilir. Dayanıklı tüketim malları sektörüne yönelik şikayetlerin incelendiği bir çalışmada da müşterilerin teknik yetersizlik, davranış, randevu ve 
GÜLER; Application Of Gray Relational Analysis Technique On Complaint Management In The Durable Goods Industry, 274-291.

bilgi vermeme konularında şikayetçi oldukları görülmüştür (Kesemen Pul, 2019, s. 69). Sektördeki şirketlerin şikayet sayılarının az olması mal ve hizmet kalitesinin yeterli olması, oluşan şikayetlerin ardından çözüm süreci ve süresi müşteri memnuniyeti yaratılması için gereklidir. Şirketlerin iletişim kanallarının yeterliliği ve aktifliği de bu süreçte etkilidir.

\section{Gri Iliş̧kisel Analiz}

Gri ilişkisel analiz (GIA) çok kriterli karar problemlerinde belirsizlik durumlarında kullanılan bir karar verme tekniğidir. GiA 1982 yılında Deng tarafından geliştirilmiş olup eksik, belirsiz ve yetersiz bilgi ile karşılaşılınca farklı alanlarda karar vermeye yardımcı bir yöntem olarak kullanılmaktadır (Deng, 1988, s. 1). Gri sistem teorisinde belirsizliğin olmadığı tam bilgi durumu beyaz, eksik bilgi ya da belirsizlik gri ile ifade edilmiştir. Eksik bilgiye sahip olan sistem gri sistem olarak isimlendirilmiştir (Tsai, Chang ve Chen, 2003, s. 45). Gri sistem teorisinin bir parçası olan Gri ilişkisel analizde benzerlik ya da farklılık derecesine bağlı olarak ilişki ölçülmekte ve sıralama yapılmaktadır (Chen ve Ting, 2002, s. 838; Feng ve Wang, 2000, s. 136).

Gri ilişkisel analiz belirli çalışma konularında mevcut tüm durumların bir sistem içinde bütün ilişkilerini net ve kesin bir biçimde tanımlanmasını sağlamaktadır (Huang ve Lee, 2003, s. 74). Gri ilişkisel analizin birçok kriterin birlikte ele alınmasına imkan vermesi, veri sayısının az olduğu durumlarda bile değerlendirme yapılabilmesi, örneklem miktarı için katı kuralların olmaması, dağılımın bilinmediği ya da normal olmadığı durumlarda ilişki derecesine göre sıralamaya imkan vermesi şeklinde avantajları bilinmektedir (Liu ve Forrest, 2007, s. 115; Tzeng ve Tsaur, 1994, s. 90).

Gri ilişkisel analizin altı adımda uygulandığı ifade edilmektedir. Bu adımlar aşağıdaki şekildedir (Wen, 2004, s. 21; Zhai vd, 2009, s. 7072):

1- Karar matrisinin oluşturulması

$$
\begin{aligned}
& X_{1}(1), X_{2}(2) \ldots . . X_{1}(n) \\
& X_{2}(1), X_{2}(2) \ldots \ldots . X_{2}(n) \\
& X_{m}(1), X_{m}(2) \ldots X_{M}(n)
\end{aligned}
$$

2- Referans serisinin oluşturulması

3- Karşılaştırma matrisinin belirlenmesi

Farklı boyutlarda olan göstergelerin karılaştırılması için verilerin standart hale getirilmesi gerekmektedir. Aşağıdaki adımlarla veriler standart hale getirilmektedir.

$$
\begin{aligned}
& x_{i}(k)=\left\{x_{i}(k)-\min x_{i}(k)\right\} /\left\{\left(\max x_{i}(k)-\min x_{i}(k)\right\}\right. \\
& x_{i}(k)=\left\{\max x_{i}(k)-\min x_{i}(k)\right\} /\left\{\left(\max x_{i}(k)-\min x_{i}(k)\right\}\right.
\end{aligned}
$$


GÜLER; Dayanıklı Tüketim Malları Sektöründe Şikayet Yönetimine Yönelik Gri ilişkisel Analiz Tekniği Uygulaması, 274-291.

$$
\left.x_{i}(k)=1-\mid x_{i}(k)-u i\right)|/ \max | x_{i}(k)-u_{i} \mid
$$

4- Mutlak değer tablosunun belirlenmesi

Kriterlerin karakteristliklerinin baz alınması ile katsayı farklııklar hesaplanmaktadır. Katsayı farklılığı sıra sayısı ile referans değer arasındaki farklılığı ifade etmektedir.

$$
\Delta X i(k)=\left|Y_{0}(1)-X_{1}(1)\right|,\left|Y_{0}(2)-X_{1}(2), \ldots \ldots .\right| Y_{0}(n)-X_{1}(n) \mid
$$

5- Gri ilişkisel katsayı matrisi oluşturulması

Fark veri dizinin içerisinde $\Delta_{\text {enb }}$ (her dizi içindeki en büyük değişim değeri) ve $\Delta_{\text {enk }}$ (her dizi içindeki en küçük değişim değeri) değerleri bulunur. $\delta$ katsayısı genellikle 0,5 olarak alınmaktadır.

$\vartheta(j)=\left(\Delta_{\text {enk }}+\delta \Delta_{\text {enb }}\right) /\left(\Delta_{i}(j)+\delta \Delta_{\text {enb }}\right.$

6- iliş̧ki derecesi hesaplanması

Matrisin oluşması için her fark veri set için hesaplamanın yapılması ile ilişki derecesi hesaplanmaktadır.

$$
\Gamma i=1 / n \sum l_{i}(m)
$$

Gri ilişkisel analiz turizm, finans, lojistik gibi sektörlerde finansal performans değerlemelerinde (Gözkonan ve Küçükbay, 2019, s. 71; Karkacıer ve Yazgan, 2017, s. 154; Başdeğirmen ve Tunca, 2017, s. 327), kullanılmıştır. Gri ilişkisel analizin personel seçim sürecinde (Ulutaş, Özkan ve Tağraf, 2018, s. 223) ve konut alım kararı verilmesi (Uğur ve Baykan, 2017, s. 220) çalışmalarında da kullanıldığı görülmektedir.

\section{Yöntem ve Bulgular}

Bu çalışma dayanıklı tüketim malları sektöründe ürün ve hizmet sunan şirketlerin şikayet yönetimi süreçlerinin anlaşılabilmesi için yapılmıştır. Sektörde çok sayıda şirketin bulunması ve şirketlerin şikayet yönetimi politikalarının değerlendirilmesi ve şirketler arasında en etkili yönetimin belirlenmesine yönelik seçenekler ve seçeneklerin sıralanabilmesi için kriterler belirlenmiştir. Çalışmada şikayetvar.com üzerinden Aralık 2020 döneminde ilgili sektöre yönelik sitenin belirttiği bir yıllık veriler elde edilmiştir.

İlgili şirketlerin müşterilerle iletişim kanalları resmi internet siteleri üzerinden belirlenmiştir. Dayanıklı tüketim malları sektöründeki şirketlerden olan Arçelik, Beko, Bosch, Electrolux, Grundig, Profilo, Siemens, Simfer ve Vestel' in şikayet yönetimine yönelik verileri incelenmiştir. Şirketlerin şikayet yönetim kriterleri arasında literatür 
GÜLER; Application Of Gray Relational Analysis Technique On Complaint Management In The Durable Goods Industry, 274-291.

incelemeleri sırasında çözüm oranı, çözüm süresi, memnuniyet ve müşterilerin şirketlere kolay ulaşılabilirliğinin önemi oldukça fazla olduğu anlaşılmaktadır. Buna göre analize tabi tutulacak şirketlerin şikayet yönetim politikalarının anlaşımasına yönelik kriterler ve açıklamaları Tablo 1'de yer almaktadır.

Tablo 1. Kriterler

\begin{tabular}{|c|c|c|}
\hline Kod & Kriter & İçerik \\
\hline K1 & Çözüm oranı & $\begin{array}{l}\text { cevaplanan şikayet sayısı/iletilen şikayet } \\
\text { sayısı }\end{array}$ \\
\hline K2 & Şikayet çözüm süresi & yıllık ortalama süre \\
\hline K3 & Memnuniyet puanı & yıllık ortalama süre \\
\hline K4 & İletişim kanalları & şirkete ulaşılabilecek kanal sayısı \\
\hline
\end{tabular}

Kriterler, şirketler, hangi kriterlerin minimum ve hangi kriterlerin maksimum değerde olmasının istenilmesini gösteren veriler Tablo 2' de gösterilmektedir. Şirketlerin iletişim kanalları yazar tarafından şirketlerin resmi internet sayfalarından alınmıştır.

Tablo 2. Şikayet Yönetimi Politikaları Veri Seti

\begin{tabular}{lcccc}
\hline & \multicolumn{1}{c}{ Max } & Min & Max & Max \\
\hline Marka & Çözüm oranı & $\begin{array}{c}\text { Çözüm süresi } \\
\text { (Dk) }\end{array}$ & $\begin{array}{c}\text { Memnuniyet } \\
\text { Puanı }\end{array}$ & $\begin{array}{c}\text { İletişim } \\
\text { Kanalı (Adet) }\end{array}$ \\
Arçelik & 0,990 & 114 & 3 & 4 \\
Beko & 0,980 & 111 & 2,9 & 4 \\
Bosch & 0,978 & 128 & 2,4 & 2 \\
Electrolux & 0,991 & 71 & 1,9 & 2 \\
Grundig & 0,959 & 166 & 2,9 & 2 \\
Profilo & 0,983 & 124 & 2,5 & 2 \\
Siemens & 0,983 & 91 & 2,5 & 2 \\
Simfer & 0,997 & 98 & 3,7 & 2 \\
Vestel & 0,997 & 98 & 3,3 & 3 \\
\hline
\end{tabular}


GÜLER; Dayanıklı Tüketim Malları Sektöründe Şikayet Yönetimine Yönelik Gri iliş̧kisel Analiz Tekniği Uygulaması, 274-291.

Gri ilişkisel analiz yapılabilmesi için referans seriye ihtiyaç duyulmaktadır. Gri ilişkisel analiz için kriterlerden beklenen maksimum ya da minimum hali ile referans seri elde edilmiş ve Tablo 3’ de gösterilmektedir. Şikayet çözüm süreci için olumlu olan çözüm oranı, memnuniyet puanı, iletişim kanal adetinin maksimum olması, çözüm süresinin ise minimum sürede olması sürecin başarılı şekilde işlemesi için yararlı görülmektedir, buna göre referans seri belirlenmiştir.

Tablo 3. Referans Serisi Oluşturulmuş Veri Seti

\begin{tabular}{lcccc}
\hline \multicolumn{1}{c}{ Marka } & Max & Min & Max & \multicolumn{2}{c}{ Max } \\
\hline Reözüm & $\begin{array}{c}\text { Çözüm } \\
\text { oranı }\end{array}$ & süresi (Dk) & $\begin{array}{c}\text { Memnuniyet } \\
\text { Puanı }\end{array}$ & $\begin{array}{c}\text { Iletişim Kanalı } \\
\text { (Adet) }\end{array}$ \\
Arçelik & 0,997 & 71 & 3,7 & 4 \\
Beko & 0,990 & 114 & 3 & 4 \\
Bosch & 0,980 & 111 & 2,9 & 4 \\
Electrolux & 0,978 & 128 & 2,4 & 2 \\
Grundig & 0,991 & 71 & 1,9 & 2 \\
Profilo & 0,959 & 166 & 2,9 & 2 \\
Siemens & 0,983 & 124 & 2,5 & 2 \\
Simfer & 0,983 & 91 & 2,5 & 2 \\
Vestel & 0,997 & 98 & 3,7 & 3 \\
\hline
\end{tabular}

Alternatiflerin karşılaştırılabilmesi için birimlerinden arındırmak ve büyüklüklerini düşük düzeylere çekmek amacıyla Tablo 4' te normalizasyon matrisi hazırlanmıştır.

Tablo 4. Normalize Matris

\begin{tabular}{lcccc}
\hline Marka & K1 & K2 & K3 & K4 \\
\hline Arçelik & 0,810 & 0,990 & 0,682 & 1,000 \\
Beko & 0,558 & 0,991 & 0,636 & 1,000 \\
Bosch & 0,503 & 0,987 & 0,409 & 0,000 \\
\hline
\end{tabular}


GÜLER; Application Of Gray Relational Analysis Technique On Complaint Management In The Durable Goods Industry, 274-291.

\begin{tabular}{lllll}
\hline Electrolux & 0,838 & 1,000 & 0,182 & 0,000 \\
Grundig & 0,000 & 0,978 & 0,636 & 0,000 \\
Profilo & 0,615 & 0,987 & 0,455 & 0,000 \\
Siemens & 0,620 & 0,995 & 0,455 & 0,000 \\
Simfer & 1,000 & 0,994 & 1,000 & 0,000 \\
Vestel & 0,998 & 0,994 & 0,818 & 0,500 \\
\hline
\end{tabular}

Bu adımda normalize edilmiş değerler ile referans serisi arasındaki uzaklıklar hesaplanmıştır. Değerlere Tablo 5' te yer verilmektedir.

Tablo 5. Uzaklık Matrisi (Mutlak Değer Tablosu)

\begin{tabular}{lcccc}
\hline Marka & K1 & K2 & K3 & K4 \\
\hline Arçelik & 0,190 & 0,010 & 0,318 & 0,000 \\
Beko & 0,442 & 0,009 & 0,364 & 0,000 \\
Bosch & 0,497 & 0,013 & 0,591 & 1,000 \\
Electrolux & 0,162 & 0,000 & 0,818 & 1,000 \\
Grundig & 1,000 & 0,022 & 0,364 & 1,000 \\
Profilo & 0,385 & 0,013 & 0,545 & 1,000 \\
Siemens & 0,380 & 0,005 & 0,545 & 1,000 \\
Simfer & 0,000 & 0,006 & 0,000 & 1,000 \\
Vestel & 0,002 & 0,006 & 0,182 & 0,500 \\
\hline
\end{tabular}

Gri ilişkisel katsayıları, kriterlerin eşit ağırlıkta tutularak gri ilişki derecesi ve şirketlerin sıralamaları Tablo 6’ da gösterilmektedir.

Tablo 6. Gri Ilişki Katsayısı, Derecesi ve Sıralama

\begin{tabular}{|c|c|c|c|c|c|c|}
\hline \multirow[t]{2}{*}{ Marka } & \multirow[b]{2}{*}{ K1 } & \multirow[b]{2}{*}{$\mathrm{K} 2$} & \multirow[b]{2}{*}{ K3 } & \multicolumn{3}{|c|}{ Gri İlişki } \\
\hline & & & & K4 & Derecesi & Sıralama \\
\hline Arçelik & 0,725 & 0,980 & 0,611 & 1,000 & 0,829 & 2 \\
\hline
\end{tabular}


GÜLER; Dayanıklı Tüketim Malları Sektöründe Şikayet Yönetimine Yönelik Gri iliş̧kisel Analiz Tekniği Uygulaması, 274-291.

\begin{tabular}{lllllll}
\hline Beko & 0,531 & 0,981 & 0,579 & 1,000 & 0,773 & 4 \\
Bosch & 0,501 & 0,974 & 0,458 & 0,333 & 0,567 & 8 \\
Electrolux & 0,755 & 1,000 & 0,379 & 0,333 & 0,617 & 5 \\
Grundig & 0,333 & 0,957 & 0,579 & 0,333 & 0,551 & 9 \\
Profilo & 0,565 & 0,976 & 0,478 & 0,333 & 0,588 & 7 \\
Siemens & 0,568 & 0,991 & 0,478 & 0,333 & 0,593 & 6 \\
Simfer & 1,000 & 0,987 & 1,000 & 0,333 & 0,830 & 1 \\
Vestel & 0,995 & 0,987 & 0,733 & 0,500 & 0,804 & 3 \\
\hline
\end{tabular}

\section{Sonuç ve Öneriler}

Teknolojideki gelişmeler müşteri beklentilerinin artması dayanıklı tüketim malları sektöründe ürün ve hizmet sunan şirketlerin şikayet politikalarını etkinlikle yürütmelerini gerektirmektedir. Etkin şikayet yönetim politikalarının oluşturulması için şikayetin çözümü, süreçlerin iyileştirilmesi ve müşteri memnuniyetinin yaratılması sağlanmalıdır. Şikayetin çözümlenmesi sonrasında müşteri davranışları takip edilmelidir. Sektörde pek çok alternatifin yer alması nedeniyle şirketlerin rekabet edebilmeleri ve ayakta kalabilmeleri ve vizyonları doğrultusunda hareket edebilmeleri için müşterilerin beklentilerine önem vermeleri gerekmektedir. Şirketlerin iletilen her şikayet için hem müşteri memnuniyeti yaratmak hem de geliştirilmesi gereken süreçlere yönelmek için buna bir avantaj olarak bakmaları gerekmektedir. Araştırmada dayanıklı tüketim malları sektöründe ürün ve hizmet sunan dokuz şirketin şikayet politikalarına yönelik kriterlerle değerlendirme yapılması için çok kriterli karar verme yöntemlerinden olan gri ilişkisel analiz yapılmıştır.

Çalışmada kriterlere yönelik verilere şikayetvar.com isimli şikayetlerle şirketleri bir araya getiren platform olan internet sitesinden ulaşılmıştır. Şikayetvar.com müşteriler ve markalar arasında köprü görevi üstlenmekte müşterilerinin alışverişleri için karar vermelerini kolaylaştırmakta müşterilerin şikayetlerini markaya iletmelerine olanak sağlamaktadır. Markalar da şikayetleri memnuniyete dönüştürerek müşteri kitlesinin artmasına imkan bulmaktadır (sikayetvar.com). Şirketlerin müşterilerle iletişim kurdukları kanallara ise şirketlerin resmi internet siteleri aracılığıyla ulaşılmıştır.

Şirketlerin şikayet politikalarındaki etkinliklerinin belirlenmesine yönelik yapılan bu çalışmada çözüm oranı, çözüm süresi, memnuniyet puanı ve iletişim kanal sayısı kriter olarak ele alınmıştır. Yapılan analiz sonucuna göre Simfer, Arçelik ve Vestel' in ilk üç sırada yer aldığı görülmektedir. Şirketlerin müşteri beklentilerini karşılamak için süreçleri yönetmeleri şikayetin doğmasına engel olacak süreçler geliştirmeleri, şikayetleri kısa sürede çözüme ulaştırırken müşterilerin kolayca ulaşabilecekleri 
GÜLER; Application Of Gray Relational Analysis Technique On Complaint Management In The Durable Goods Industry, 274-291.

kanalları yönetmeleri ve çözüm sonrasında da müşteri memnuniyet ölçümü yapmaları etkin şikayet yönetimi için gereklidir. Şikayetlerin kısa sürede çözüme ulaştırılması ve olumlu sonuçların müşteriler açısından doğması bugün ve gelecekte şirketlerin rekabet güçlerine olumlu olarak yansıyacaktır. Analiz sonucuna göre belirtilen kriterlerde diğer şirketlere göre farklılık gösteren şirketlerin ilk sıralarda yer aldığı görülmektedir.

Çalışmada şirketlerin şikayet yönetimi politikalarındaki etkililiklerinin belirlenmesi için belirli bir dönem baz alınmış ve kriterler eşit olarak değerlendirilmiştir. Bundan sonraki yapılacak araştırmalarda farklı dönemlerdeki verilerin incelenmesi ve kriterler kapsamında farklı yorumlara gidilmesi ya da farklı analiz teknikleri ile sonuçların ortaya çıkartılması karşılaştırma yapılabilmesine olanak sağlayacaktır. Bu çalışmada ulaşılan sonuçların şirketlerin şikayet yönetimi politikalarının düzenlenmesinde alanla ilgilenen araştırmacılara ve yöneticilere yararlı olacağı düşünülmektedir.

\title{
"Dayanıklı Tüketim Malları Sektöründe Şikayet Yönetimine Yönelik Gri Iliş̧kisel Analiz Tekniği Uygulaması" Başlıklı Makalenin Araştırma ve Etik Beyanı Bilgileri
}

\author{
Bu çalışma "Araştırma ve Yayın Etiği" değerlerine uygun olarak \\ Hazırlanmıştır.
}

Bilgilendirme
Yazar Çıkar
Çatışması Beyanı
Yazar Katkı Oranı
Beyanı

Çalışma herhangi bir bildiri veya tez benzeri çalışmadan üretim değildir.

Çalışmada herhangi bir çıkar çatışması bulunmamaktadır.

Teşekkür

Çalışmada teşekkür gerektiren bir durum bulunmamaktadır.

Etik Kurul Onay

Belgesi

Çalışmada etik kurul onayı gerekmemektedir. 

274-291.

\section{Kaynakça}

Alabay, M. N. (2010). Geleneksel Pazarlamadan Yeni Pazarlama Yaklaşımlarına Geçiş Süreci. Süleyman Demirel Üniversitesi Iktisadi ve İdari Bilimler Fakültesi Dergisi, 15(2), 213-235.

Barlow, J. ve Claus M. (2009). Her Şikâyet Bir Armağandır İşler Ters Gittiğinde Müşteri Sadakatini Yeniden Nasıl Kazanırsınız. İstanbul: Rota Yayınları.

Başdeğirmen, A. ve Tunca, M. Z. (2017). Lojistik Sektöründe Faaliyet Gösteren İşletmelerin Finansal Performanslarının Gri İlişkisel Analiz İle Değerlendirilmesi. Süleyman Demirel Üniversitesi, İktisadi ve İdari Bilimler Fakültesi Dergisi, 22(2), 327-340.

Blöndal, M.R. (2017). Consumer Complaint Behaviour on Facebook and Twitter Brand Pages. PhD Thesis, https://skemman.is/handle/1946/28660.

Burucuoğlu, M. (2011). Müşteri Memnuniyeti ve Sadakatini Arttırmada Müşteri Şikayetleri Yönetiminin Etkinliği: Bir Örnek Olay İncelemesi. Yüksek Lisans Tezi, Karamanoğlu Mehmetbey Üniversitesi Sosyal Bilimler Enstitüsü.

Butelli, S. (2007). Consumer Complaint Behavior (CCB): A Literature Review. Newcastle: Northumbria University. https://www.semanticscholar.org.

Chen, C.N. ve Ting, S.C. (2002). A Study Using The Grey System Theory To Evaluate The Importance of Various Service Quality Factors. International Journal of Quality and Reliability Management, 19(7), 838-861.

Cho, Y., ve Hiltz, R. (2002). An Analysis of Online Customer Complaints: Implications for Web Complaint Management. Proceedings of the 35th Hawaii International Conference on System Sciences.

Çiftçi, F. (2019). Ağızdan Ağıza Illetişimin Tüketicilerin Beyaz Eşya Satın Alma Kararları Üzerindeki Etkisi (Batman İli Örneği). Batman Üniversitesi, Sosyal Bilimler Enstitüsü, Yayınlanmamış Yüksek Lisans Tezi.

Deng, J. (1988). Introduction To Grey System Theory. The Journal Of Grey System I, 1(1), 124.

Eleren, A. (2007). Markaların Tüketici Tercih Kriterlerine Göre Analitik Hiyerarşi Süreci Yöntemi ile Değerlendirilmesi: Beyaz Eşya Sektöründe Bir Uygulama. Celal Bayar Üniversitesi Yönetim ve Ekonomi Dergisi, 14 (2), 49-50.

Feng, C. M. \& Wang, R.Tsu (2000). Performance Evaluation For Airlines Including The Consideration Of Financial Ratios. Journal of Air Transport Management, 6, 133142. 
GÜLER; Application Of Gray Relational Analysis Technique On Complaint Management In The Durable Goods Industry, 274-291.

Gökdeniz, İ., Bozacı, İ., ve Karakaya, E. (2011). Şikayet Yönetim Süreci Sonrası Memnuniyeti Etkileyen Faktörler Üzerine Uygulamalı Bir Araştırma. Selçuk Üniversitesi Sosyal Bilimler Enstitüsü Dergisi, 26, 173-185.

Gözkonan, Ü.H. ve Küçükbay, F. (2019). Katılım Bankaları Ile Geleneksel Bankaların ÇKKV Yöntemleri ile Performans Değerlendirilmesi: TOPSIS ve Gri illişkisel Analiz Yöntemleri İle Karşılaştırmalı Analiz. International Journal Of Economic \& Administrative Studies, 25, 71-93.

Harrison Walker, L. J. (2001). E-Complaning: A Content Analysis Of An Internet Complaint Forum. Journal Of Services Marketing, 15(5), 397-412.

Heung, V. C. ve Lam, T. (2003). Customer Complaint Behaviour towards Hotel Restaurant Services. International Journal of Contemporary Hospitality Management, 15(5), 283-289.

Huang, Chi-Chun and Hohn-Ming, Lee, (2003), A Novel Partial-Memory Learning Algorithm Based On Grey Relational Structure, Advances Intelligent Data Analysis V. Fifth International Symposium On Intelligent Data Analysis IDA Proceedings, Berlin, Germany, 68-75.

Januszewski, S. I. (2004). The Role of Service Quality and Expectations in Explaining Customer Complaints. University of California, San Diego.

Karkacıer, O. ve Yazgan, A. E. (2017), Turizm Sektöründe Gri Illişkisel Analiz (Gia) Yöntemiyle Finansal Performans Değerlemesi. Selçuk Üniversitesi Sosyal Bilimler Enstitüsü Dergisi, 37, 154-162.

Kesemen Pul, G. (2019). Beyaz Eşya Sektöründe Müşteri Şikayetlerinin Değerlendirilmesi: Bir Uygulama. Bahçeşehir Üniversitesi, Sosyal Bilimler Enstitüsü, Yayımlanmamış Yüksek Lisans Tezi.

Kozak, M., (2007), Turizm Sektöründe Tüketicilerin Şikayetlerini Bildirme Eğilimleri. Celal Bayar Üniversitesi Yönetim ve Ekonomi Dergisi, 14(1), 136-151.

Köse, E., (2007), Müşteri Sadakati Sağlamada Araçsal Bir Yöntem Olarak Şikayet Yönetimi. Yüksek Lisans Tezi, Marmara Üniversitesi Sosyal Bilimler Enstitüsü, İstanbul.

Kraemer, M. U., Yang, C. H., Gutierrez, B., Wu, C. H., Klein, B., Pigott, D.M., du Plessis, L., Faria, N. R., Li, R., Hanage, W.P., Brownstein, J. S. (2020). The Effect of Human Mobility and Control Measures on the COVID-19 Epidemic in China. Science, 368(6490), 25-45.

Liu, S. \& Forrest, J. (2007). The Current Developing Status On Grey System Theory. The Journal of Grey System. 2, 111-123.

Mensah, J.K.B. (2016). Effectiveness Of Customer Complaint Handling And its Impact On Customer Retention: The Case Of Unibank Ghana Limited. PhD Thesis, Department 
GÜLER; Dayanıklı Tüketim Malları Sektöründe Şikayet Yönetimine Yönelik Gri iliş̧kisel Analiz Tekniği Uygulaması, 274-291.

of Marketing and Corporate Strategy of the Kwame Nkrumah University of Science and Technology, Ghana.

Odabaşı, Y. (2000), Satışta ve Pazarlamada Müşteri illişkileri Yönetimi. Sistem Yayıncılık, İstanbul.

Plymine, J. (1991). Complaints as Opportunities. Journal Of Service Research, 5(1), 61-65.

Ramsey, R. D. (2016). How to Handle Customer Complaints. American Salesman, 61(2), 1724.

Robert, J., Sandy, M. (2002). Best Practice Complaint Management. Academy of Management Executive, 16 (4), 145-154.

Scriabina, N. ve Fomichov, S. (2007). 6 Ways to Benefit From Customer Complaints. American Society for Quality, Vancouver Section (408).

Supriaddin, N., Palilati, A., Bua, H. and Patwayati, H.J. (2015). The Effect Of Complaint Handling Toward Customers Satisfaction. Trust And Loyalty To Bank Rakyat Indonesia (Bri) Southeast Sulawesi, Int. J. Eng. Sci, (IJES), 4 (6), 01-10.

Süper Office, www.superoffice.com, (Erişim tarihi: 18.12.2020).

Şikayetvar.com, www.sikayetvar.com, (Erişim tarihi: 18.12.2020 ve 28.08.2021).

Tsai, C.H., Chang, C.L. ve Chen, L. (2003). Applying Grey Relational Analysis to The Vendor Evaluation Model. International Journal of The Computer, The Internet and Management, 11(3), 45-53.

Tronvoll, B. (2008). Customer Complaint Behaviour in Service. Karlstads University, Faculty of Economic Sciences, Communication and IT, Service Research Center, PhD Thesis, Sweden.

Türkiye Beyaz Eşya Sanayicileri Derneği, www.turkbesd.org (Erişim Tarihi: 27.12.2020).

Tzeng, G.H, and Tsaur, S.H. (1994), The Multiple Criteria Evaluation of Grey Relation Model. The Journal of Grey System, 6(3), 87-108.

Uğur, L.O. ve Baykan, U. N. (2017). Konut Satın Alma Kararı Verilmesinde Gri İlişkisel Analiz Tekniği Uygulaması. Düzce Üniversitesi Bilim ve Teknoloji Dergisi, 5, 220-230.

Ulutaş, A., Özkan, A.M. ve Tağraf, H. (2018). Bulanık Analitik Hiyerarşi Süreci ve Bulanık Gri Illişkisel Analizi Yöntemleri Kullanılarak Personel Seçimi Yapılması. Electronic Journal Of Social Sciences, 17(65), 223-232.

Ventura, K. (2013). Marka Kaçınması: Beyaz Eşya Markalarına Yönelik Kalitatif Bir Uygulama. Uludağ Üniversitesi, İktisadi ve İdari Bilimler Fakültesi Dergisi, 32(1), 53-76.

Wen, Kun-Li (2004), The Grey System Analysis and Its Application in Gas Breakdown and Var Compensator Finding. International Journal of Computational Computing, 2(1), 2144. 
GÜLER; Application of Gray Relational Analysis Technique On Complaint Management In The Durable Goods Industry, 274-291.

Yılmaz, C., Varnalı, K. ve Kasnakoğlu, B.T. (2016). How Do Firms Benefit From Customer Complaints. Journal Of Business Research, 69(2), 944-955.

Zhai, L.Y., Khoo, L.P. ve Zhong, Z.W. (2009), Design Concept Evaluation in Product Devolopment Using Rough Sets and Grey Relation Analysis. Expert System with Applications 36, 7072-7079. 


\title{
Application Of Gray Relational Analysis Technique On Complaint Management In The Durable Goods Industry
}

\author{
Hale Nur GÜLER
}

\section{Extended Abstract}

Complaint management policies have become even more important in companies due to the developing technology, the increase in customer expectations and the ability of customers to convey their complaints through many channels. Customers are waiting for solutions for their problems by conveying their opinions about the companies and can send comments through many channels for solutions they are not satisfied with. Companies need successful complaint management policies in order to prevent complaints and to solve complaints effectively. It is necessary for companies to effectively understand customer expectations, to go beyond what is expected and to solve the resulting complaints, and accordingly, to continuously improve their goods and services. Since there are many alternatives in the industry, companies need to create effective and successful customer experiences in order to survive and maintain their competitiveness. In this context, the complaint also has important effects on determining the image of companies. It is known that companies that regard every complaint as a gift, manage their policies accordingly, improve their processes and positively affect customers due to the complaints received.

Complaints arise when expectations are not met and dissatisfaction occurs as a result of the goods or services received. The negative feedback of the consumer who buys the product or service is a complaint. Among the durable consumer goods, the white goods sector, generally large household appliances and small household appliances are produced. According to the Turkish White Goods Manufacturers Association (TÜRKBESD), the white goods sector is one of the leading sectors with its employment contribution and efficiency in exports. Companies that produce goods and services in the white goods sector, which are in many sectors, also need effective complaint management policies. It is very important for companies to find channels that customers can reach easily, get quick solutions and be satisfied with the solutions they receive. In the study conducted for the durable consumer goods sector, it has been seen that word of mouth has an effect on brand preferences. 
Gray relational analysis (GRA) is a decision making technique used in uncertainty situations in multi-criteria decision problems. GIA was developed by Deng in 1982 and is used as a method to assist decision making in different areas when faced with incomplete, uncertain and insufficient information. Gray relational analysis provides a clear and precise definition of all the relationships in a system of all existing situations in certain study subjects. The advantages of gray relational analysis are that it allows many criteria to be considered together, can be evaluated even in cases where the number of data is low, there are no strict rules for sample size, and it allows sorting according to the degree of relationship in cases where the distribution is not known or not normal. Gray relational analysis has been used in financial performance evaluations in sectors such as tourism, finance and logistics. It is seen that the gray relational analysis is also used in the personnel selection process and in the housing purchase decision making studies.

This study was conducted to understand the complaints management processes of companies that provide products and services in the durable consumer goods sector. There are many companies in the sector, the evaluation of the complaints management policies of the companies and the options for determining the most effective management among the companies and the criteria are determined in order to rank the options. In the study, one-year data was obtained from the website for the relevant sector in the period of December 2020, over sikayetvar.com. The communication channels of the related companies with the customers are determined through their official websites. Complaint management data of Arçelik, Beko, Bosch, Electrolux, Grundig, Profilo, Siemens, Simfer and Vestel, which are companies in the durable consumer goods sector, were analyzed. It is understood that among the complaints management criteria of the companies, the resolution rate, solution time, satisfaction and easy accessibility of the customers to the companies are very important. According to the results of the analysis, it is seen that Simfer, Arçelik and Vestel are in the top three places. It is necessary for companies to manage processes to meet customer expectations, develop processes that will prevent complaints from arising, manage the channels that customers can easily reach while resolving complaints in a short time, and measure customer satisfaction after the solution. Resolving complaints in a short time and positive results for customers will reflect positively on the competitiveness of companies today and in the future. 